\title{
Opposing Role, Depending on the Stage, of PU.1 during Erythroid Differentiation
}

\section{Shinichiro Takahashi ${ }^{1,2 *}$}

${ }^{1}$ Division of Molecular Hematology, Kitasato University Graduate School of Medical Sciences, 1-15-1 Kitasato, Miniami-ku, Sagamihara, Kanagawa 252-0373, Japan ${ }^{2}$ Division of Hematology, Kitasato University School of Allied Health Sciences, 1-15-1 Kitasato, Miniami-ku, Sagamihara, Kanagawa 252-0373, Japan

PU.1 is a member of the Ezb transformation-specific sequence family of transcription factors and is expressed mainly in granulocytic, monocytic and B-lymphoid cells [1]. The downregulation of PU.1 was reported to play a role in the pathogenesis of various hematological malignancies, including Acute Myeloid Leukemia (AML) [2], multiple myeloma [3] and Myelodysplastic Syndrome (MDS) [4]. PU.1 is also normally present in immature erythroid cells [5], and several reports have indicated that their downregulation is required for erythroid terminal differentiation [6-9].

Constitutive upregulation of PU.1 is believed to be the main cause for a blockade in the differentiation process of Murine Erythroleukemia (MEL) cells [6-9]. However, several findings [10-12] indicate a requirement for PU.1 expression for erythroid differentiation. Back et al. [10] have reported an important study. They produced a line of PU.1 deficient mice carrying a green fluorescent protein reporter at this locus. They revealed that, PU.1 deficient fetal erythroid progenitors lose their self-renewal capacity and undergo proliferation arrest, premature differentiation and apoptosis [10]. A recent study by Wantakal et al. [11] demonstrated that PU.1 regulates an extensive network of genes that constitute major pathways for controlling the growth and survival of immature erythroid cells. They further revealed that fetal liver erythroid progenitors, the earliest erythroid-committed cells, are dramatically reduced in vivo in mice with low PU.1 expression [11].

The use of DNA Methyltransferase (DNMT) inhibitors in MDS, AML, Chronic Myeloid Leukemia (CML) and sickle cell anemia is becoming an effective options for these diseases [12]. Recently, my research group examined whether the effects of DNMT inhibitor, 5-aza 2'-deoxycytidine (5-azadc), are correlated with PU.1 expression in PU.1-transgenic CML derived K562 cells [13]. We demonstrated that therapeutic concentrations of 5-azadc induce erythroid differentiation of these cells, that PU.1 expression is tightly related to the effect of the agent, and that sufficient PU.1 expression accelerates erythroid differentiation and apoptosis induced by 5 -azadc [13]

These reports suggest that sufficient expression of PU.1 is necessary for erythroid differentiation. One possible explanation for this discrepancy, between those of employing MEL cells, is that K562 cells express the endogenous $\varepsilon$-globin and $\gamma$-globin genes, but not the adult stage-specific $\beta$-globin gene, and have therefore been considered as a model for the embryonic-fetal stages of erythroid development $[14,15]$. Wantakal's study [11], as well as Back's study [10], employed fetal liver erythroid progenitors from mice, which is also analyzing the embryonic-fetal stages. On the other hand, MEL cells are considered to be a model for fetal-adult development [15], which are employed in most of the previous studies analyzing the functions of PU.1 during erythroid differentiation [6-9].

Collectively, the roles of PU.1 differ during the erythroid differentiation stages. PU.1 expression inhibits erythroid differentiation in a certain stage, however, in the very immature stage, PU.1 expression is necessary for initiating erythroid differentiation. Therefore, PU.1 is a critical, versatile regulator in promoting or preventing erythroid differentiation.

\section{References}

1. Chen HM, Zhang P, Voso MT, Hohaus S, Gonzalez DA, et al. (1995) Neutrophils and monocytes express high levels of PU.1 (Spi-1) but not Spi-B. Blood 85: 2918-2928.

2. Rosenbauer F, Wagner K, Kutok JL, Iwasaki H, Le Beau MM, et al. (2004) Acute myeloid leukemia induced by graded reduction of a lineage-specific transcription factor, PU.1. Nat Genet 36: 624-630.

3. Pettersson M, Sundström C, Nilsson K, Larsson LG (1995) The hematopoietic transcription factor PU.1 is downregulated in human multiple myeloma cell lines. Blood 86: 2747-2753.

4. Huh HJ, Chae SL, Lee M, Hong KS, Mun YC, et al. (2009) CD34, RAB20, PU.1 and GFI1 mRNA expression in myelodysplastic syndrome. Int J Lab Hemato 31: $344-351$

5. Pop R, Shearstone JR, Shen Q, Liu Y, Hallstrom K, et al. (2010) A key commitment step in erythropoiesis is synchronized with the cell cycle clock through mutual inhibition between PU.1 and S-phase progression. PLoS Biol 8.

6. Kihara-Negishi F, Suzuki M, Yamada T, Sakurai T, Oikawa T (2005) Impaired repressor activity and biological functions of PU. 1 in MEL cells induced by mutations in the acetylation motifs within the ETS domain. Biochem Biophys Res Commun 335: 477-484.

7. Rao G, Rekhtman N, Cheng G, Krasikov T, Skoultchi Al (1997) Deregulated expression of the PU.1 transcription factor blocks murine erythroleukemia cell terminal differentiation. Oncogene 14: 123-131.

8. Yamada T, Kondoh N, Matsumoto M, Yoshida M, Maekawa A, et al. (1997) Overexpression of PU.1 induces growth and differentiation inhibition and apoptotic cell death in murine erythroleukemia cells. Blood 89: 1383-1393.

9. Yamada T, Abe M, Higashi T, Yamamoto H, Kihara-Negishi F, et al. (2001) Lineage switch induced by overexpression of Ets family transcription factor PU.1 in murine erythroleukemia cells. Blood 97: 2300-2307.

10. Back J, Dierich A, Bronn C, Kastner P, Chan S (2004) PU.1 determines the selfrenewal capacity of erythroid progenitor cells. Blood 103: 3615-3623.

11. Wontakal SN, Guo X, Will B, Shi M, Raha D, et al. (2011) A large gene network in immature erythroid cells is controlled by the myeloid and $\mathrm{B}$ cell transcriptiona regulator PU.1. PLoS Genet 7: e1001392.

12. de Vos D, van Overveld W (2005) Decitabine: a historical review of the development of an epigenetic drug. Ann Hematol 1: 3-8.

13. Aoyama S, Nakano H, Danbara M, Higashihara M, Harigae H, et al. (2012) The differentiating and apoptotic effects of 2-aza-5'-deoxycytidine are dependent on

*Corresponding author: Shinichiro Takahashi, Division of Hematology, Kitasato University School of Allied Health Sciences, 1-15-1 Kitasato, Miniami-ku, Sagamihara, Kanagawa 252-0373, Japan, Tel: +81-42-778-8216; Fax: +81-42778-8216; E-mail: shin@kitasato-u.ac.jp

Received April 23, 2012; Accepted April 25, 2012; Published April 27, 2012

Citation: Takahashi S (2012) Opposing Role, Depending on the Stage, of PU.1 during Erythroid Differentiation. J Blood Lymph 2:e108. doi:10.4172/2165$7831.1000 \mathrm{e} 108$

Copyright: (C) 2012 Takahashi S. This is an open-access article distributed unde the terms of the Creative Commons Attribution License, which permits unrestricted use, distribution, and reproduction in any medium, provided the original author and source are credited. 
Citation: Takahashi S (2012) Opposing Role, Depending on the Stage, of PU.1 during Erythroid Differentiation. J Blood Lymph 2:e108. doi:10.4172/2165$7831.1000 \mathrm{e} 108$

Page 2 of 2

the PU.1 expression level in PU.1-transgenic K562 cells. Biochem Biophys Res Commun 420: 775-781.

14. Donze D, Townes TM, Bieker JJ (1995) Role of erythroid Kruppel-like factor in human gamma- to beta-globin gene switching. J Biol Chem 270: 1955-1959.
15. Wall L, Destroismaisons N, Delvoye N, Guy LG (1996) CAAT/enhancer-binding proteins are involved in beta-globin gene expression and are differentially expressed in murine erythroleukemia and K562 cells. J Biol Chem 271: 16477 16484. 